\title{
Association between Organizational Commitment and Personality Traits of Faculty Members of Ahvaz Jundishapur University of Medical Sciences
}

\author{
Farzad Faraji Khiavi ${ }^{1}$, Rezvan Dashti ${ }^{2}$, Saeedeh Mokhtari ${ }^{3}$
}

${ }^{1}$ Ph.D., Assistant Professor, Department of Health Services Administration, School of Health, Social Determinants of Health Research Center, Ahvaz Jundishapur University of Medical Sciences, Ahvaz, Iran

${ }^{2}$ M.Sc. in Rehabilitation Administration, School of Rehabilitation, Social Determinants of Health Research Center, Ahvaz Jundishapur University of Medical Sciences, Ahvaz, Iran

${ }^{3}$ B.Sc. in Health Services Administration, School of Health, Social Determinants of Health Research Center, Ahvaz Jundishapur University of Medical Sciences, Ahvaz, Iran

\section{Type of article: Original}

\begin{abstract}
Introduction: Individual characteristics are important factors influencing organizational commitment. Also, committed human resources can lead organizations to performance improvement as well as personal and organizational achievements. This research aimed to determine the association between organizational commitment and personality traits among faculty members of Ahvaz Jundishapur University of Medical Sciences.

Methods: the research population of this cross-sectional study was the faculty members of Ahvaz Jundishapur University of Medical Sciences (Ahvaz, Iran). The sample size was determined to be 83. Data collection instruments were the Allen and Meyer questionnaire for organizational commitment and Neo for characteristics' features. The data were analyzed through Pearson's product-moment correlation and the independent samples ttest, ANOVA, and simple linear regression analysis (SLR) by SPSS.

Results: Continuance commitment showed a significant positive association with neuroticism, extroversion, agreeableness, and conscientiousness. Normative commitment showed a significant positive association with conscientiousness and a negative association with extroversion $(p=0.001)$. Openness had a positive association with affective commitment. Openness and agreeableness, among the five characteristics' features, had the most effect on organizational commitment, as indicated by simple linear regression analysis.

Conclusion: Faculty members' characteristics showed a significant association with their organizational commitment. Determining appropriate characteristic criteria for faculty members may lead to employing committed personnel to accomplish the University's objectives and tasks.

Keywords: organizational commitment, personal characteristics, faculty members, university
\end{abstract}

\section{Introduction}

In the current era, human resources are considered as the most important capital of the organizations, and higher quality of the capital increases the likelihood of success, survival, and promotion of the organization. According to some experts in management science, if organizations want to fully achieve their objectives by having clear goals, optimal strategies, efficient organizational structures, and proper jobs design, they require competent and committed human resources (1). Therefore, it is necessary to improve the quality of human resources, because it would benefit both the organization and the individuals. It seems that, regardless of the size, desires, and inner motivations of people in the organization, achieving the organizational goals will be very difficult (2). One of the attitudes and motivational issues that are focused by resources management and organizational and psychological behavior studies today, that is effective in human resources and organizational performance productivity, is the organizational

\section{Corresponding author:}

Rezvan Dashti, School of Rehabilitation, Ahvaz Jundishapur University of medical sciences, Ahvaz, Iran.

Tel: +98.6133738269, Fax: +98. 6133738282, Email: rezvan.dashti@gmail.com

Received: October 02, 2015, Accepted: December 06, 2015, Published: March 2016

iThenticate screening: November 28, 2015, English editing: February 18, 2016, Quality control: March 06, 2016

(C) 2016 The Authors. This is an open access article under the terms of the Creative Commons Attribution-NonCommercialNoDerivs License, which permits use and distribution in any medium, provided the original work is properly cited, the use is non-commercial and no modifications or adaptations are made. 
commitment and the predictors that affect it. Organizational commitment, as an important occupational and organizational attitude, is simply the belief in the values and goals of the organization, a sense of loyalty to the organization, moral obligation, heart's desire and need to stay in the organization (3). Three components are considered for organizational commitment: 1) Emotional commitment: the tendency of people to share their energy and loyalty to continue their work in the organization; 2) Continuous commitment: willingness to do continuous activities based on the recognition of costs associated with leaving the organization; and 3) Normative commitment: feeling of duty to remain as a member of the organization (4). One of the most important predictors of organizational commitment is the attention to the personality and characteristics and individual differences of staff. Paying attention to the personality and dimensions and characteristics of the individuals is one of the issues that always can help organizations achieve their objectives and organizational efficiency and become the creativity development source or root of many organizational problems and can have effects on action, behavior, decisions, and organizational behavior (5). The first and foremost component of an organization system is the human resources with their different personalities, so the motivations, abilities, desires, ideas, and thoughts that are actually important tools forming the human personality, determine the people's expectations toward each other and also toward the organization. One of the most important classifications about the personality traits that has been confirmed at different times and cultures and also is used in this study is the classification of Costa and McCrae (6). Using factor analysis, they concluded that five major features can be considered among the differences: 1) Neuroticism (emotional stability), 2) Extroversion, 3) Flexibility (experience), 4) Agreeableness (spirit of the agreeability), and 5) Conscientiousness (Job consciousness). Personality traits form the foundation of the behavioral system and are important and influential in determining and predicting staff's organizational behavior in the future, such as leaving the job, delay, negligence, absenteeism, their organizational commitment, and also all processes related to their recruitment, transfer, and appointment to organizational jobs. Because they have realized that they can obtain a framework for predicting the employees' behavior by identifying these features and employees' personalities, and help the management of the system in this way to appoint qualified people in different positions, reduce the displacement of employees, and increase job satisfaction (7). Jaafari et al (8) maintained Schroder's (9) findings that predictors of organizational commitment are organizational policies, the job itself, payments, work conditions, and promotion. However, according to Ahmadian and Askarian (10), the organizational commitment is mostly about loyalty to the organization and considering the consequences of leaving the organization. Sepahvand and Shariatnejad (11) mentioned some theories that organizational commitment is emotional attachment and involving with the organization, and accepting its values. Considering a relatively large number of requests from new faculty members for transfer to other universities in Ahvaz University of Medical Sciences, it seemed convenient to do some research on particular basic variables, such as personal traits. So far, studies have been conducted to investigate individuals' organizational commitment based on personality traits or relationship between these two variables in the industrial sector, such as Choghtai, Glad, and Emmanuel Camillery (12-14). However, only a few studies have been done in the health sector, and they include the study of Bahrami et al., which was conducted on the nurses in Yazd (15). Since administrators can use the preliminary estimates of personality traits of faculty members to make decisions about their participation in achieving the organization's goals, the present study aimed to determine the association between organizational commitment and personality traits of faculty members of Ahvaz Jundishapur University of Medical Sciences.

\section{Material and Methods}

\subsection{Setting, sampling, and inclusion criteria}

This was an analytical study in which the data were collected in a cross-sectional method. The study population consisted of 612 faculty members of Ahvaz Jundishapur University of Medical Sciences. The determined sample size due to the coefficient $r=0.44, \alpha=0.01$ and $z(1-\alpha / 2)=2.57$ with a confidence level of $99 \%$ and $z(1-\beta)=1.68$ with test power of $95 \%$ was 83 . Stratified random sampling was used to distribute questionnaires among respondents. Inclusion criteria were the formal, contractual, or projective membership of Faculty of Ahvaz Jundishapur University of Medical Sciences. Tuition faculty members and people with other titles began teaching at the University and also people who did not want to cooperate with the investigation were excluded. Not formal faculty members and individuals teaching with other titles at the University and also individuals who did not want to cooperate were excluded from the investigation.

\subsection{Instrument and data collection}

The research tools of the two questionnaires consisted of Costa and McCrae's NEO personality inventory (16) and organizational commitment of Allen \& Meyer (17). The neo-standard questionnaire consisted of 60 questions that 
evaluated the five dimensions of personality traits, including neuroticism, extraversion, openness to experience, flexibility, and conscientiousness. Each of the 5 areas was measured by 12 questions, which were responded to by a 5-point Likert scale (strongly agree, agree, no comment, disagree, and strongly disagree). Allen and Meyer's organizational commitment questionnaire had 24 items and 3 subscales (affective commitment, continuous commitment, normative commitment) that each of these dimensions was measured by 8 questions using the Likert method. The validity of the questionnaires was approved by five specialized professors. In this study, Cronbach's alpha of personality traits and organizational commitment questionnaires were calculated as 0.88 and 0.81 , respectively (27). Questionnaires were distributed among the faculty members of various colleges within six weeks and were collected after completion. Data distribution was normal, and data analysis was performed using Pearson's product-moment correlation, the independent samples t-test, ANOVA, and simple linear regression analysis (SLR) in SPSS software.

\subsection{Research ethics}

Licensure and an introduction letter from the college explaining the purpose of the study and the need for it to faculty members of Ahvaz Jundishapur University and retention of personal information of respondents were of the research ethical considerations.

\section{Results}

In this study, 40 females (48.19\%) and 43 males (51.81\%) were investigated. Demographic information of the research population is presented in Table 1.

Table 1. Absolute and relative frequency distribution of demographic characteristics of subjects

\begin{tabular}{|l|l|l|l|}
\hline Variable & Classification & $\mathrm{n}$ & $\%$ \\
\hline Gender & Male & 43 & 51.81 \\
\cline { 2 - 4 } & Female & 40 & 48.19 \\
\hline Age & $31-40$ & 33 & 39.75 \\
\cline { 2 - 4 } & $41-50$ & 32 & 38.55 \\
\cline { 2 - 4 } & $51-60$ & 18 & 21.70 \\
\hline Education & MA & 29 & 34.93 \\
\cline { 2 - 4 } & PhD & 54 & 65.07 \\
\hline Science Ranking & Educator & 31 & 37.36 \\
\cline { 2 - 4 } & Assistant Professor & 46 & 55.42 \\
\cline { 2 - 4 } & Associate Professor & 3 & 3.61 \\
\cline { 2 - 4 } & Professor & 3 & 3.61 \\
\hline \multirow{5}{*}{ Employment Status } & Contractual & 25 & 30.11 \\
\cline { 2 - 4 } & Formal & 50 & 60.26 \\
\cline { 2 - 4 } & Projective & 8 & 9.63 \\
\hline College & Medical & 13 & 15.66 \\
\cline { 2 - 4 } & Pharmacy & 13 & 15.66 \\
\cline { 2 - 4 } & Paramedical & 17 & 20.48 \\
\cline { 2 - 4 } & Rehabilitation & 14 & 16.88 \\
\cline { 2 - 4 } & Nursing & 13 & 15.66 \\
\cline { 2 - 4 } & Hygiene & 137 & 100 \\
\hline Total & & & \\
\hline
\end{tabular}

As can be seen in Table 1, in age distribution, $39.75 \%$ of the faculty members were in the age group of $31-40$ years. The lowest frequency was in the age group of 51-60 years with $21.70 \%$ relative frequency. Fifty-four individuals (65.07\%) of those studied had doctorate degrees, which were the most frequent. Forty-six individuals (55.42\%) were assistant professors who had the highest number. The lowest frequency was for associate professors and professors, and $37.36 \%$ of the respondents were educators. More than sixty percent were formal employed faculty members who had the highest percentage. Mean score of personality traits was calculated as $44.15 \pm 3.35$ and estimated to be relatively good. Mean scores of personality traits' subscales were calculated as $39.13 \pm 6.53$ for neuroticism, $42.7 \pm$ 5.3 for extraversion, $40.7 \pm 3.77$ for flexibility, and $48.47 \pm 47$ for conscientiousness. These scores represented a relatively good situation of the mentioned characteristics. Agreeableness personality trait represented the very good 
situation with a mean score of $49.55 \pm 4.36$. Agreeableness and neuroticism had the highest and lowest ratings, respectively, among the personality traits dimensions. Organizational commitment in faculty members was estimated to be relatively strong with a mean score of $25.91 \pm 2.8$. Organizational commitment dimensions of affective, continuous, and normative commitments were calculated as $28.54 \pm 2.4,24.11 \pm 4.4$, and $25.08 \pm 1.8$, respectively. All three subscales were estimated to be relatively strong in this study. The results of studying the association between personality traits and dimensions of organizational commitment are shown in Table 2 . There was a positive, significant, and large association between personal traits of neuroticism and continuous commitment. There was a positive, significant, and medium association between the personal traits of extraversion and continuous commitment. And there was a negative, significant, and small association between the personal traits of extraversion and normative commitment. The model of personality traits affecting on the organizational commitment concluded via simple linear regression analysis. This model is demonstrated in Table 3. SLR results in Table 3 showed that the personality traits of flexibility and agreeableness had the greatest impact on organizational commitment and the dimensions of flexibility and agreeableness might predict $23 \%$ of the organizational commitment changes. Accordingly, simple linear regression analysis equation of organizational commitment based on predictor variables is as follows: Organizational Commitment $=11.99+$ (Agreeableness) $0.716+$ (Flexibility) 0.871.

Table 2. Relationship between dimensions of personality traits and organizational commitment

\begin{tabular}{|l|l|l|l|l|l|}
\hline Personality traits & Statistical indicator & $\begin{array}{l}\text { Organizational } \\
\text { commitment }\end{array}$ & $\begin{array}{l}\text { Normative } \\
\text { commitment }\end{array}$ & $\begin{array}{l}\text { Continuous } \\
\text { commitment }\end{array}$ & $\begin{array}{l}\text { Affective } \\
\text { commitment }\end{array}$ \\
\hline \multirow{2}{*}{ Neuroticism } & Pearson coefficient & 0.299 & -0.153 & 0.650 & 0.170 \\
\cline { 2 - 6 } & p-value & 0.006 & 0.167 & 0.000 & 0.124 \\
\hline \multirow{2}{*}{ Extroversion } & Pearson coefficient & 0.295 & -0.075 & 0.457 & 0.221 \\
\cline { 2 - 6 } & p-value & 0.007 & 0.000 & 0.000 & 0.044 \\
\hline Flexibility & Pearson coefficient & 0.368 & 0.089 & 0.185 & 0.377 \\
\cline { 2 - 6 } & p-value & 0.001 & 0.426 & 0.094 & 0.000 \\
\hline \multirow{2}{*}{ Agreeableness } & Pearson coefficient & 0.318 & 0.018 & 0.613 & 0.146 \\
\cline { 2 - 6 } & p-value & 0.003 & 0.869 & 0.000 & 0.187 \\
\hline Conscientiousness & Pearson coefficient & 0.370 & 0.261 & 0.441 & 0.161 \\
\cline { 2 - 6 } & p-value & 0.001 & 0.017 & 0.000 & 0.146 \\
\hline
\end{tabular}

Table 3. Simple linear regression analysis of personality traits that affect organizational commitment

\begin{tabular}{|l|l|l|l|l|}
\hline Variables & Regression coefficients & Beta & T & p-value \\
\hline Constant coefficient & 11.987 & & 0.808 & 0.422 \\
\hline Flexibility & 0.871 & 0.316 & 3.160 & 0.002 \\
\hline Agreeableness & 0.716 & 0.301 & 3.006 & 0.004 \\
\hline
\end{tabular}

\section{Discussion}

The results of this study showed that there is a significant and large association between personality traits of neuroticism and continuous commitment. This means that individuals who have high scores in this dimension have high emotional stability and do not have any tendency to experience psychological distress in the form of anxiety, anger, depression, shame, hatred, or negative emotions. They also have the ability to control their desires and use effective strategies to deal with stress. As a result, they have high continuous commitment in the organization. Mousavi and Majidi (18) concluded in their study that there was a significant, positive, and medium association between these two variables, which is in line with the present study. Furthermore, the results of Lonzberry et al. (19) and Chang and Lee (20) are consistent with the current study. Personality trait of extraversion has positive, significant, and medium association with the continuous commitment, and it has a negative, significant, and small association with the normative commitment. It means that the people who pay more attention to outside have direct and average continuous commitment and weak and reverse normative commitment compared to those whose behaviors are resulted from subjective evaluation and internal factors. In extroverted people, positive emotions and extroversion are related to their organizational commitment and consequently their organizational health, because positive emotions are the behavioral core of this type of individuals. Bahrami et al. (15) reported in their study that the organizational commitment in extroverted people is significantly more than introverted ones, which is in line with the findings of the present study. Gray et al. (21) also concluded that personality type of individuals does not have a significant association with their organizational commitment. Emanuel Camilleri (14) reported in his study 
that personality traits, such as introversion and extroversion, have a significant association with organizational commitment, which also is consistent with the current study. The results of this study showed that there is a significant and medium association between the personality trait of flexibility and affective commitment. It means that the people whose life experiences are rich are willing to accept new ideas and unconventional values, and they tend to have high positive and negative emotions and have an average emotional commitment in an organization. Also, people who have a sense of belonging, security, prosperity, loyalty, and conscientiousness are committed to their organization, participate in the organization, and enjoy being a member of that organization. Mousavi and Majidi (18) reported in a similar study that there was medium and positive association between the personality traits of flexibility and organizational commitment of the employees, which is in line with the current study. Moreover, Chang and Lee obtained similar results in their study (20). People with this kind of trait are receptive to new ideas and have a broad range of interests. Due to introspection, these people usually disagree with others, and their thinking and methods may be quite different from those of others. They are gifted and curious people and have a strong, wise, and exquisite imagination with a wide range of interests; and since they are curious about the inner and the outer world and their life is full of experience, this flexibility can be a factor to reduce occupational stress and increase organizational commitment. According to the results of this study, it can be said that organizational commitment as a kind of organizational behavior is partly influenced by flexibility. So, the most important thing that universities can focus on is to consider personality traits, such as flexibility, when they are recruiting. The results showed that there is a positive, significant, and large association between the personality traits of agreeableness and continuous commitment. This means that people who want altruism, compassion, and helping others have a high continuous commitment to the organization. These people are sympathetic, considerate, and warm. It is easy to deal with them, and they are pleasant individuals that are enjoyable to be with. The results of SLR showed that among the dimensions of personality traits, this one has the greatest impact on organizational commitment. Since teaching needs altruistic people who are eager to help students, when selecting individuals for employment as teachers, it is appreciated to examine these important personality traits as well as the scientific and general competencies in order to recruit people who are more committed to the organizational goals and values governing the university.

According to the results of this study, the personality trait of conscientiousness had positive and significant medium association with continuous commitment, and small association with normative commitment. This means that those with high scores in this dimension who are highly accurate, punctual, and reliable and tend to have great success, and have a sense of responsibility in carrying out their duties, have good continuous commitment and weak normative commitment within the organization. These people are usually reliable, logical and highly productive, and are very accurate at timely completion of duties. They are idealist people and their behavior is based on ethical standards. Pour Yusef and Azadfallah (22) reported in their study that there was a significant association between the personality trait of conscientiousness and organizational commitment. The people with the personality trait of conscientiousness have more organizational commitment than others, which is in line with the results of the present study. Mousavi and Majidi (18) stated in their study that there was positive and medium association between the personality trait of conscientiousness and organizational commitment, which also was consistent with the results of the present study. Selecting competent employees is an operation that is done to reform, grow, and develop human beings. Considering personality dimensions, such as conscientiousness of people in the organization, can help organizations achieve the necessary efficiency, because these people are very careful and fastidious in their work and try to accomplish their mission properly. Organizational commitment has an important role in improving the health of the labor force and ignoring it will lead to non-optimal efficiency.

In this study, no significant association was observed between the demographic characteristics, including gender, age, scientific rank, education, and employment status and any of the personality traits and dimensions of organizational commitment. Bahrami et al. (15) stated that the introverted formal employees had the lowest organizational commitment, but this difference was not significant in extroverted people. The difference of organizational commitment in introverted nurses was significant based on their age so that older people had lower commitment; but this difference was not significant in extroverted people, which is inconsistent with the results of this study. Camilleri (14) found a significant association between the employees' ages and their organizational commitment in his study, which is not consistent with the results of this study. Gray et al. (21) found in their study that there is no significant association between organizational commitment and gender and education, personality type and gender and education, which is in accordance with the results of the present study. It should be noted that some researchers have shown that personality traits could influence variables, such as organizational commitment and their job performance. According to some research, personality traits are among the best predictors of employees' performance $(23,24)$. Based on the results of the current study, it can be concluded that personality traits 
of faculty members should be considered as one of the determinants of their organizational commitment in human resource management practices. The most important limitation of research was that some of faculty members considered personality traits very personal and were not interested in answering the questionnaire. After explaining the research objectives, they gave their consent to participate in the research.

\section{Conclusions}

With regard to the significant association between personality traits and organizational commitment in the present study, it is suggested that more studies be conducted to determine the appropriate indicators of appropriate personality traits for faculty members so that the recruited people have the necessary commitment to objectives and tasks of the university. Work type compatibility with the individual's personality trait in human resources productivity as well as meeting the needs according to Maslow pyramid, may lead the person to self-actualization, which is important in personal and social performance of the person and organization. Paying attention to personality traits, especially empiricism factors such as considering ingenuity and creativeness, creates mechanisms for openness and curiosity, flexibility, and wisdom in academic research and training affairs are essential, as well as agreeableness factors, such as good humor, kindness and empathy.

\section{Acknowledgments:}

The source of the data used in this paper was the B.Sc. thesis of Saideh Mokhtari, a student at the Ahvaz Jundishapur University of Medical Sciences. Financial support was provided by Ahvaz Jundishapur University of Medical Sciences. The University's Ethics Committee issued ethics code IR.AJUMS.REC.1394.425 for this research.

\section{Conflict of Interest:}

There is no conflict of interest to be declared.

\section{Authors' contributions:}

All authors contributed to this project and article equally. All authors read and approved the final manuscript.

\section{References}

1) Rezaeyan A. Fundamentals of Organization \& Management. Tehran: SAMT Publishation; 2008

2) Mousavi S, Majidi A. Study the Relation between Personality Characteristics and Organizational Commitment at one of the Military Organization in Tehran. Journal of police Medicine. 2013; 3(8): 159-66.

3) Allen J, Meyer N. Affective, continuance and normative commitment to the organization: An examination of construct validity. J Vocat Behav. 1996; 49: 252-76. doi: 10.1006/jvbe.1996.0043. PMID: 8980084.

4) Mandeni H, Zahedi MJ. Preference Determination of Effective Factors on the Organizational Personnel Commitment. Iran J Sociology. 2005; 6: 3-33.

5) Khanifar H, Moghimi SM, Jandaghi GR, Taheri F, Sayar A. Managers Personality Knowing Requisite for Management of Organizational Behavior (A case study of five factors model of personality in Qom University of Medical Sciences); Iran. J Health Adm. 2009; 12: 49-56.

6) McCrae RR, Costa PT. Validation of the five-factor model of personality across instruments and observers. J Pers Soc Psychol. 1987; 52(1): 81-90. doi: 10.1037/0022-3514.52.1.81. PMID: 3820081.

7) Robins SP, Debi S, Divirai. Organizational Behavior. Translated by Aarabi SM, Hamid Rafiei MA, Asrari Ershad B, 4th ed, Tehran 2006: Cultural Studies Office Publisher; 1998.

8) Jaafari P, Ghourchian N, Behboodian J, Shahidi N. Developing a Structural Model for Relationships among Self-efficacy, Competencies and Organizational Commitment with Teaching Quality of Faculty Members. Quarterly Journal of Research and Planning in Higher Education. 2012; 18(2): 61-82.

9) Schroder R. Predictors of Organizational Commitment for Faculty and Administrators of a Private Christian University. Journal of Research on Christian Education. 2008; 17(1): 81-97. doi: 10.1080/10656210801968299.

10) Ahmadian L, Askarian M. Study of the relationship between educational departments climate and organizational commitment by student affairs professor of the faculty of psychology and social sciences in Islamic Azad university- Tehran central branch. Research in Educational Systems. 2014; 7(23): 79-93.

11) Sepahvand R, Shariatnejad A. The effect of managerial competence on job satisfaction and organizational commitment of the faculty and staff of the Universities of Khorramabad city. Organizational Culture Management. 2014; 12(3): 505-28. PMCID: PMC3964876. 
12) Chughtai AA. Antecedents and consequences of organizational commitment among Pakistan university teachers. HRM. 2006; 11(1): 39-64.

13) Gelade GA. National differences in organizational commitment: Effect of economy, product of personality or concequences of culture? Journal of cross-cultural psychology. 2006; 37(5): 542-56. doi: $10.1177 / 0022022106290477$.

14) Cammileri E. Some antecedents of organizational commitment: Results from an information systems public sector organization. Malta, Bank of Volleta review, 25; 2002.

15) Bahrami MA, Emamrezaei A, Sattar E, Ranjbar Ezzatabadi M, Dehghani Tafti A. the Comparative Survey of Organizational Commitment Based on Personal Traits: A Case Study on Nurses in Yazd Training Hospitals. Toloo-e-Behdasht. 2010; 2-3(29); 44-55.

16) Costa PT, McCrae RR. The NEO personality inventory manual. Odessa, FL: Psychological Assessment Resources; 1985.

17) Jaros S. Meyer and Allen Model of Organizational Commitment: Measurement Issues. Icfai. 2007; 6(4): 7 25.

18) Mousavi S, Majidi A. Study the Relation between Personality Characteristics and Organizational Commitment at one of the Military Organization in Tehran. Journal of police Medicine. 2013; 3: 159-166.

19) Launsbery JW. Moffitt L. Gibson LW. Drost AW. Stevens M. An investigation of personality traits in relation to job and career satisfaction of information technology professionals. Journal of information technology. 2007; 1: 46-51. doi: 10.1057/palgrave.jit.2000094.

20) Chang, Su-Chao \& Lee Ming-Shing. Relationships among personality traits, job Characteristics, job Satisfaction and Organizational Commitment- an Empirical Study in Taiwan. The business review, Cambridge. 2006; 3: 201-7.

21) Gari S. A survey on the relationship between personalities (introversion and extraversion) and job satisfaction and organizational commitment in nurses of teaching and treatment centers of Ghazvin. EDRAK Magazin Science. 2010; 14: 20-24.

22) Pooryousef S, Azadfallah P. The Relationship between Personality-Redated Characteristic, Organizational Commitment and Staff Conferontation Methods. Journal of psychology. 2013; 16: 355-69.

23) Judge TA, Bono JE . Relationship of core self-evaluations traits-self steem, generalized self-efficacy, locus of control and emotional stability - with job satisfaction and job performance: Ameta-analysis. J Appl Psychol. 2001; 86(1): 80-92. doi: 10.1037/0021-9010.86.1.80. PMID: 11302235.

24) Khosravi M. Personality symmetry with informatics job. Informatics sciences journal. 2003; 18(3\&4): 53 9. 